Check for updates

The BMJ

Cite this as: BMJ 2021;375:n2860 http://dx.doi.org/10.1136/bmi.n2860 Published: 19 November 2021

\title{
Covid-19: AstraZeneca says its antibody drug AZD7442 is effective for preventing and reducing severe illness
}

\section{Elisabeth Mahase}

AstraZeneca's antibody treatment AZD7442 reduces the risk of developing symptomatic covid-19 when it is taken as a preventive measure, the company has said, and also reduces the risk of severe illness and death when taken shortly after symptoms start.

The drug is currently being tested in two separate trials, which reported that when taken as a prophylactic AZD7442 reduced the risk of symptomatic covid- 19 by $83 \%$ and when taken three days after symptom onset it cut the risk of severe illness or death by $88 \%$.

In both trials the antibody combination was generally well tolerated, with no new safety issues identified in the six month analysis of the prevention trial. The findings, issued through a company press release, will be submitted for publication in a peer reviewed medical journal.

AZD7442 is a combination of two long acting antibodies (LAABs), tixagevimab and cilgavimab-both derived from B cells donated by patients who recovered from SARS-CoV-2 infection. The human monoclonal antibodies were developed by Vanderbilt University Medical Center in Nashville, Tennessee, and licensed to AstraZeneca in June 2020.

The treatment is being produced with support from the US government. AstraZeneca has agreed to supply the US government with 700 ooo doses, if the treatment is granted emergency use authorisation by the US Food and Drug Administration. AstraZeneca has submitted an application for AZD7442 as a prophylactic treatment for covid-19.

The UK had initially planned to purchase one million AZD7442 doses, but a deal has still not been agreed. ${ }^{1}$

Commenting on the announcement, Dipender Gill, clinical pharmacology and therapeutics lecturer at St George's, University of London, said, “The key question now is how the various monoclonal antibody therapies for covid-19 should be clinically implemented. Furthermore, the role of monoclonal antibodies once oral SARS-CoV-2 antiviral agents become available is also not clear, particularly as their therapeutic window and target populations are likely to overlap, and that antivirals can be taken from home."

\section{Prevention}

The Provent phase III trial looked at the safety and efficacy of a $300 \mathrm{mg}$ injection of AZD7442 for the prevention of covid-19 in unvaccinated people who did not have signs of previous SARS-CoV-2 infection. It was conducted across 87 sites in the US, UK, Spain, France, and Belgium, with 5197 adults randomised in a 2:1 ratio to receive a single dose of either $300 \mathrm{mg}$ of AZD7442 (3460 people) or saline placebo (1737).
The six month assessment was based on 4991 participants, with data collected up to 29 August 2021. Approximately $43 \%$ of participants were aged 60 or over, and more than $75 \%$ had baseline comorbidities and other characteristics associated with an increased risk of severe covid-19.

The analysis found that one $300 \mathrm{mg}$ dose of AZD7442 reduced the risk of developing symptomatic covid-19 by $83 \%$, when compared with placebo. There were no cases of severe covid-19 or covid related deaths in participants treated with AZD7442 at either the primary or six month analyses. In the placebo arm there were five cases of severe covid-19 and two covid related deaths.

\section{Severe illness}

The other phase III trial, called Tackle, assessed the safety and efficacy of a single injection of $600 \mathrm{mg}$ of AZD7442 against placebo in non-hospitalised adults with mild to moderate covid-19 who had had symptoms for less than seven days.

It included 903 participants who were randomised (1:1) to receive either AZD7442 (452 people) or saline placebo (451). Around $13 \%$ of participants were 65 or over, and 90\% had baseline comorbidities and other characteristics that put them at high risk of progression to severe covid-19.

The analysis found that at day 29 AZD7442 reduced the risk of developing severe covid-19 or death (from any cause) by $88 \%$ when compared with placebo in patients who had been symptomatic for three days or less at the time of treatment.

Ring S. UK reconsidering plan to buy Astra covid antibody drug. Bloomberg. May 2021. https://www.bloomberg.com/news/articles/2021-05-12/u-ksaid-to-reconsider-plan-to-buy-astra-covid-antibody-drug.

This article is made freely available for use in accordance with BMJ's website terms and conditions for the duration of the covid-19 pandemic or until otherwise determined by BMJ. You may use, download and print the article for any lawful, non-commercial purpose (including text and data mining) provided that all copyright notices and trade marks are retained. 